\title{
CONSTANT EVOLUTION OF THE INTERNATIONAL SYSTEM OF UNITS (SI) (Message from the BIML Director)
}

\section{Stephen Patoray}

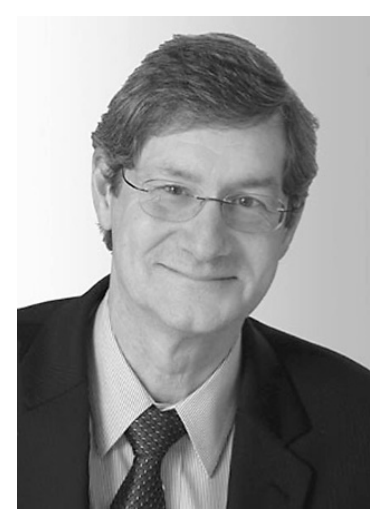

The theme chosen for World Metrology Day 2018 is Constant evolution of the International System of Units (SI). This evolution is a culmination of many years of work by a large number of dedicated metrologists to determine the best method of redefining several of the base SI units. This revision will not directly impact legal metrology, since users will be able to obtain traceability to the revised SI from the same sources used at present. However, it does mean that there will be a change in the way we define certain units of measurement and, in some cases, how traceability may ultimately be established.

The revised SI will be entirely based on constants of nature. While this may seem to be a big change, it has in fact already happened several times in the recent past, when both the second (1967/68) and the metre (1983) were redefined from being based on the earth's movement and size to being based on atomic and electromagnetic constants.

The significance in this case is that certain concepts that were taught to most of us at school and which were up to now almost carved in stone may now change. The platinum-iridium (Pt-Ir) prototype that is kept under three locks in a vault near Paris will go into partial retirement after 137 years of service.

Certainly this will mark the end of an era. The SI started out as the MKS system with human sized standards based on what at that time were considered to be invariants of nature: the rotation of the earth, its size, and a weight originally derived from a certain amount of water (later agreed on as a specific amount of Pt-Ir). Better measurements proved over time that those invariants were not in fact as invariant as previously thought; that fact, together with the technological advances applied to measurements that have gradually allowed for much more accurate realization of the units, are the main reasons for the change. Now the last of those original standards will be replaced by a definition based on a fundamental constant of nature.

Although 'Le Grand K' is the most famous of the SI artifacts, changes will also happen in other units. The kelvin will no longer depend on a property of water, the ampere will not be based on a definition that is very difficult to realize, and the mole will change to a more practical definition. In addition, the revised definitions of the kilogram, ampere, kelvin and mole will have no impact on the definitions of the second, the metre and the candela.

As stated earlier, we do not expect there to be an impact on legal metrology, but it is a significant change in the thinking and the methods of all of us who have been working with these units for many years.

We invite you to take a few minutes to review the many documents available on the BIPM website related to this topic. We also hope you enjoy celebrating World Metrology Day with us again this year and look forward to once again marking the importance that metrology plays in the activities of our daily life.

International Organization of Legal Metrology (BIML). Published in Izmeritel'naya Tekhnika, No. 5, p. 4, May, 2018. 